\title{
Room-temperature phosphorescence determination of melamine in dairy products using L-cysteine-capped Mn-doped zinc sulfide ( $\mathrm{ZnS}$ ) quantum dots
}

\author{
Buket Er Demirhan, ${ }^{*}$ Burak Demirhan, ${ }^{*}$ and H. Eda Satana Kara† ${ }^{1}$ \\ *Department of Food Analysis, and \\ †Department of Analytical Chemistry, Faculty of Pharmacy, Gazi University, 06330 Ankara, Turkey
}

\begin{abstract}
A simple, sensitive, and precise room-temperature phosphorescence method was developed for the determination of melamine in dairy products using Lcysteine-capped Mn-doped zinc sulfide $(\mathrm{ZnS})$ quantum dots as a probe. This method is based on the quenching of the phosphorescence signal of quantum dots by the interaction with melamine. Under optimum conditions, phosphorescence intensity was quenched by various concentrations of melamine in a linear range from 50 to $500 \mathrm{ng} / \mathrm{mL}$, with a detection limit of $5.95 \mathrm{ng} / \mathrm{mL}$ in $10 \mathrm{~m} M$ phosphate buffer ( $\mathrm{pH}$ 7.4). The relative standard deviation for 5 replicate measurements was $0.15 \%$. The developed method was applied to dairy products to determine melamine concentrations; recovery values ranged from 96.3 to $104.7 \%$.
\end{abstract}

Key words: room-temperature phosphorescence, milk product, melamine, quantum dot

\section{INTRODUCTION}

Melamine (MEL; 1,3,5-triazine-2,4,6-triamine) is a trimer of cyanamide and is a nitrogen-rich chemical (Figure 1). The combination of MEL with triazines and cyanuric acid causes insoluble crystals to form in the kidneys, resulting in renal failure and bladder cancer (Vara Messler et al., 2012; Chansuvarn et al., 2013; Chang et al., 2014). Melamine is widely used in the manufacturing of plates, kitchenware, plastic products, paper, and glues. Although MEL may be used in the manufacturing of packaging for food products, it is not approved for direct addition to human food or animal feeds. Because of its high nitrogen level, MEL increases the protein level, but it cannot be detected by the Kjeldahl method. Melamine is inexpensive and easily accessible and thus is illegally added to proteinrich foods such as milk products to enhance the protein content (Vara Messler et al., 2012; Cao et al., 2013). In

Received December 10, 2014.

Accepted January 30, 2015.

${ }^{1}$ Corresponding author: eda@gazi.edu.tr many countries, the allowed limits of MEL are $1 \mathrm{ppm}$ for infant formulas and $2.5 \mathrm{ppm}$ for other food (Wang et al., 2014). According to the Turkish Food Codex (TFC), the levels of melamine should not exceed $1 \mathrm{mg} /$ $\mathrm{kg}$ in powdered infant formula and $2.5 \mathrm{mg} / \mathrm{kg}$ in food (other than infant formula; TFC, 2012). Therefore, a simple and sensitive method is needed for the detection of MEL in dairy products.

Determination of MEL concentrations in proteinbased food products such as milk products is important to prevent or detect adulteration. To date, several methods have been used for determination of MEL in milk products, including HPLC with detection systems such as UV (Yan et al., 2012, Beltran-Martinavarro et al., 2014), fluorescence (Finete et al., 2014; Zhang et al., 2014), mass spectrometry (Duan et al., 2011; Hassani et al., 2013; Khedr, 2013; Shin et al., 2014), capillary electrophoresis (Vallejo-Cordoba and Aaron, 2010; Katou and Wu, 2012; Vachirapatama and Maitresorasun, 2013; Wu and Yu, 2013; Himmelsbach and Thanh Vo, 2014; Kong et al., 2014), GC-MS (Koh et al., 2011; Jurado-Sanchez and Ballesteros, 2011; Pan et al., 2013; Wong and Mok, 2013), electrochemical methods (Araujo and Paixao, 2014; Guo et al., 2014; Xu et al., 2014; Xue et al., 2014), and spectrophotometry (Huang et al., 2010; Chansuvarn et al., 2013; Li et al., 2013; Liu et al., 2014). However, many of these methods are not suitable for routine analysis because of their complicated, time-consuming, and high-cost features. In particular, spectrophotometric methods require a derivatization step. Therefore, simple, sensitive, fast, and low-cost methods need to be developed.

Since their development, fluorescent quantum dots (QD) have increasingly replaced traditional organic fluorophores. Quantum dots are semiconductor nanoparticles with some advantages over organic and inorganic fluorophores: good optical properties, stability against photobleaching and chemical reaction, size-control luminescence, broad excitation bands and sharp emission bands, as well as high photoluminescence efficiency (Ren and Yan, 2012). Because of these properties, QD are widely used as fluorescent probes for analysis of various analytes. Typically, fluorescent QD 
are constructed from inorganic semiconductor core materials such as cadmium telluride $(\mathrm{CdTe})$ or cadmium selenium (CdSe). Fluorescent QD have also been used in determination of MEL. These methods are based on fluorescence resonance energy transfer between MEL and different QD such as CdTe (Tang et al., 2013) and cadmium sulfide (CdS; Wang et al., 2012) or an inner filter effect of $\mathrm{Au}$ and $\mathrm{Ag}$ nanoparticles on the fluorescence of CdS (Cao et al., 2013), CdTe (Zhang et al., 2012), and ZnSe (Cao et al., 2014).

In this study, a room-temperature phosphorescence (RTP) method was developed for selective detection of MEL. Compared with fluorescence techniques, RTP is more selective and sensitive, and it has a longer emission lifetime and wider Stokes shift (Matsuoka and Yoshimura, 2010). Therefore, L-cysteine-capped Mn-doped zinc sulfide (ZnS) QD were synthesized and characterized. The use of different dopants can strongly modify the optical, electrical, and magnetic character of QD. Compared with traditional QD such as CdTe or $\mathrm{CdSe}, \mathrm{ZnS}$ is an attractive semiconductor for doping to produce new types of quantum dots; $\mathrm{Mn}^{2+}$ and $\mathrm{Zn}^{2+}$ have equal electric charge and similar ionic radii, so $\mathrm{Mn}^{2+}$ can be easily incorporated into the $\mathrm{ZnS}$ crystal lattice without producing a great effect. Thus, $\mathrm{ZnS}$ is a more attractive host nanoparticle for doping to form QD with unique phosphorescence properties. Manganese-doped ZnS QD exhibit phosphorescence emission when excited at $290 \mathrm{~nm}$. The working mechanism of these probes is based on quenching of their phosphorescence intensities. This type of QD has been used in the phosphorescent sensing of drugs and biomolecules without the need for any sample pretreatment.

The aim of this study was to synthesize L-cysteinecapped Mn-doped ZnS QD and use them as the probe to detect MEL. Melamine quenches the phosphorescence signal of Mn-doped ZnS QD. Based on this procedure, we propose a new method for MEL detection and quantification. The method allows the sensitive, selective, and rapid detection of MEL in dairy products.

\section{MATERIALS AND METHODS}

\section{Materials and Chemicals}

L-Cysteine, $\mathrm{ZnSO}_{4}, \mathrm{MnCl}_{2}$, and $\mathrm{Na}_{2} \mathrm{~S}$ (Merck, Darmstadt, Germany) were used for the preparation of Mn-doped ZnS QD. Melamine was obtained from Acros Organics (Geel, Belgium). Trichloroacetic acid $\left(\mathrm{C}_{2} \mathrm{HCl}_{3} \mathrm{O}_{2}\right)$ was obtained from Merck. A stock solution of $500 \mu \mathrm{g} / \mathrm{mL}$ MEL was prepared in deionized water and stored at $5{ }^{\circ} \mathrm{C}$. Solutions of different concentrations of MEL were prepared by dilutions in buffer solution. All reagents were of analytical grade. Phosphate buf-

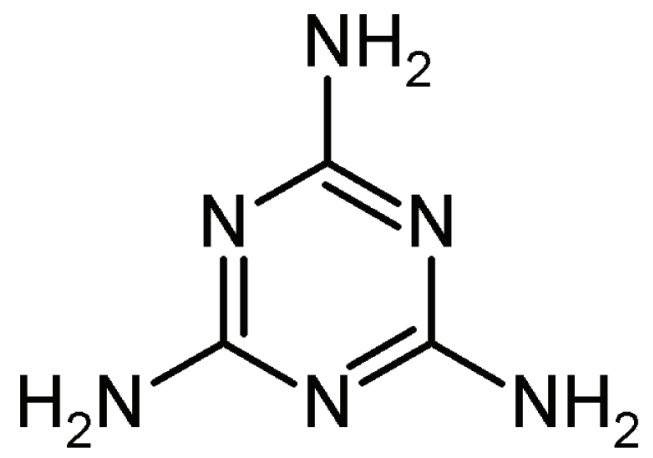

Figure 1. Structural formula of melamine.

fer (0.01 $M, \mathrm{pH} 7.4)$ was prepared in deionized water and the $\mathrm{pH}$ was adjusted using $5 \mathrm{M}$ sodium hydroxide. Buffer solution and sodium hydroxide ( 1 and $5 M$ ) were prepared using analytical-grade reagents and deionized water. Deionized water $(18.2 \mathrm{M} \Omega \cdot \mathrm{cm}$, Simplicity, MilliQ water purification system; Millipore, Billerica, MA) was used for the preparation of aqueous solutions. In this study, commercial milk products (yogurt, cream, white cheese, coffee creamer, and follow-on milk) were collected from markets in Ankara Province, Turkey.

\section{Apparatus}

The phosphorescence measurements were performed with a Varian Cary Eclipse spectrofluorimeter with a 10- $\times 10-\mathrm{mm}$ quartz cuvette (Varian, Palo Alto, CA). Excitation wavelength and slit widths were 290 and 10 $\mathrm{nm}$, respectively. A xenon flash lamp was used as the light source.

Ultraviolet-visible spectrometric measurements were carried out using Shimadzu 160 A spectrometer (Shimadzu, Tokyo, Japan). The measurements were done using a pair of $10 \times 10$-mm-path-length quartz cells. The $\mathrm{pH}$ measurements were performed using a combined $\mathrm{pH}$ electrode with an Orion model $720 \mathrm{~A} \mathrm{pH}$ meter (Thermo Orion, Beverly, MA). An MSE Mistral1000 type centrifuge (Loughborough, UK), J. P. Selecta type sonicator (J. P. Selecta, Barcelona, Spain), and vortex (Firlabo, Lyon, France) were used in sample preparation throughout the studies. Samples and standards were filtered using a $0.45-\mu \mathrm{m}$ filter (Sartorius, Goettingen, Germany). All experiments were done at room temperature.

\section{Synthesis of Mn-Doped ZnS QD}

Synthesis of the Mn-doped ZnS QD was carried out in aqueous solution based on a published method with a minor modification (Wang et al., 2009). In this ex- 
periment, $50 \mathrm{~mL}$ of $0.02 M$ L-cysteine, $5 \mathrm{~mL}$ of 0.1 $M \mathrm{ZnSO}_{4}$, and $1.5 \mathrm{~mL}$ of $0.01 \mathrm{M} \mathrm{MnCl}_{2}$ were added to a flask and mixed. Then, the $\mathrm{pH}$ of the mixture was adjusted to 11 with $1 \mathrm{M} \mathrm{NaOH}$. After stirring, argon gas was passed through the flask contents at room temperature for $30 \mathrm{~min}$ to remove air, and $5 \mathrm{~mL}$ of $0.1 \mathrm{M} \mathrm{Na}_{2} \mathrm{~S}$ was added quickly to the solution to allow nucleation of the nanoparticles. The mixture was stirred for $20 \mathrm{~min}$, and then the solution was aged at $50^{\circ} \mathrm{C}$ in the open air for $2 \mathrm{~h}$ to form L-cysteine-capped Mn-doped ZnS QD.

\section{Sample Preparation}

Two milliliters of milk sample or $1 \mathrm{~g}$ of dairy product such as yogurt, cream, cheese, or coffee creamer was transferred to centrifuge tubes, and $15 \mathrm{~mL}$ of $1 \%$ TCA was added. This mixture was vortexed thoroughly, placed in an ultrasonic bath for $20 \mathrm{~min}$, and then centrifuged at 2,400 $\times g$ for 15 min at room temperature. The supernatant was transferred to a $25-\mathrm{mL}$ flask and filtered through a $0.45-\mu \mathrm{m}$ filter, and the $\mathrm{pH}$ was then adjusted to 7.4 (Gong et al., 2013).

\section{Phosphorescence Experiments}

Phosphorescence measurements were carried out at an excitation wavelength of $290 \mathrm{~nm}$ in the absence and presence of MEL. One hundred microliters of QD was diluted with $10 \mathrm{~m} M$ phosphate buffer solution ( $\mathrm{pH}$ 7.4), and different volumes of MEL solution were added to detect the phosphorescence-quenching effect. Phosphorimetric measurements were done 2 min after the reaction was initiated.

\section{RESULTS AND DISCUSSION}

\section{Characterization of the $Q D$}

L-Cysteine-capped Mn-doped ZnS QD were synthesized based on the reaction of zinc sulfate, manganese chloride, and sodium sulfide in aqueous solution, as described in the Synthesis of Mn-Doped ZnS QD section. Morphologies of QD have been characterized by He et al. (2008); QD have a spherical shape and almost uniform size (diameter of about $3.5 \mathrm{~nm}$; He et al., 2008). The diameter of Mn-doped ZnS QD was calculated by using equation [1] (Fortes et al., 2011)

$$
\begin{gathered}
\mathrm{D}=9.8127 \times 10^{-7} \lambda^{3}-1.7147 \times 10^{-3} \lambda^{2} \\
+1.0064 \lambda-194.84
\end{gathered}
$$

where $\mathrm{D}$ is the diameter of the $\mathrm{QD}$ and $\lambda$ is the wavelength of emission maximum. The calculated diameter of the Mn-doped ZnS QD prepared in this study was $3.5 \mathrm{~nm}$.

The QD showed a broad UV absorption band between 200 and $300 \mathrm{~nm}$, with 2 maxima around 209 and 290 nm (Figure 2a). Phosphorescence of L-cysteine-capped Mn-doped ZnS QD was not observed without the aging step, but QD exhibited a phosphorescence emission peak at $590 \mathrm{~nm}$ when excited at $290 \mathrm{~nm}$ after aging at $50^{\circ} \mathrm{C}$ under open air for $2 \mathrm{~h}$ (Figure $2 \mathrm{~b}$ ). This emission band is $\mathrm{pH}$-dependent and stable in the range of $\mathrm{pH} 7.0$ to 8.5 (He et al., 2008). The prepared QD were stable in water for at least $5 \mathrm{mo}$ in the dark at $4^{\circ} \mathrm{C}$, without notable precipitation, and the phosphorescence signal of QD was stable during this period (data not shown).

\section{Optimization of $\mathrm{pH}$}

The phosphorescence intensity of the Mn-doped ZnS QD was pH dependent. As shown in Figure 3a, in acidic solution, the phosphorescence intensity of Mn-doped ZnS QD was low. The phosphorescence intensity increased steadily up to $\mathrm{pH} 7.4$, was stable in the range of $\mathrm{pH} 7.4$ to 8.0, and then decreased sharply from $\mathrm{pH}$ 8.0 to 9 (Figure $3 \mathrm{a}$ ). The quenched phosphorescence intensity also changed with $\mathrm{pH}$ : it was stable between pH 7.4 and 8.0 and then decreased sharply (Figure 3b). Thus, a pH of 7.4 was selected for this method.

\section{Reaction Time}

We investigated the effect of reaction time on the phosphorescence intensity of Mn-doped ZnS QD in $\mathrm{pH}$ 7.4 phosphate buffer. The RTP intensity of QD was quenched quickly upon addition of MEL and the reaction reached equilibrium within $2 \mathrm{~min}$, after which time the signal was stable. Therefore, the QD-MEL solutions were analyzed after 2 min (Figure 4).

\section{Interferences}

One objective of this study was to apply the developed method to determine the presence of MEL in dairy products. It is known that ions from salts in the samples can affect the RTP signal. Therefore, effects of many common ions such $\mathrm{Ca}^{2+}, \mathrm{Mg}^{2+}, \mathrm{K}^{+}, \mathrm{Na}^{+}$were examined. The RTP intensities of L-cysteine-capped Mn-doped ZnS QD and QD-MEL system were not affected by a 500-fold concentrations of $\mathrm{K}^{+}, \mathrm{Na}^{+}, \mathrm{Ca}^{2+}$, and $\mathrm{Mg}^{2+}$. No significant change in signal was observed. Thus, the developed method can be used for the analy- 

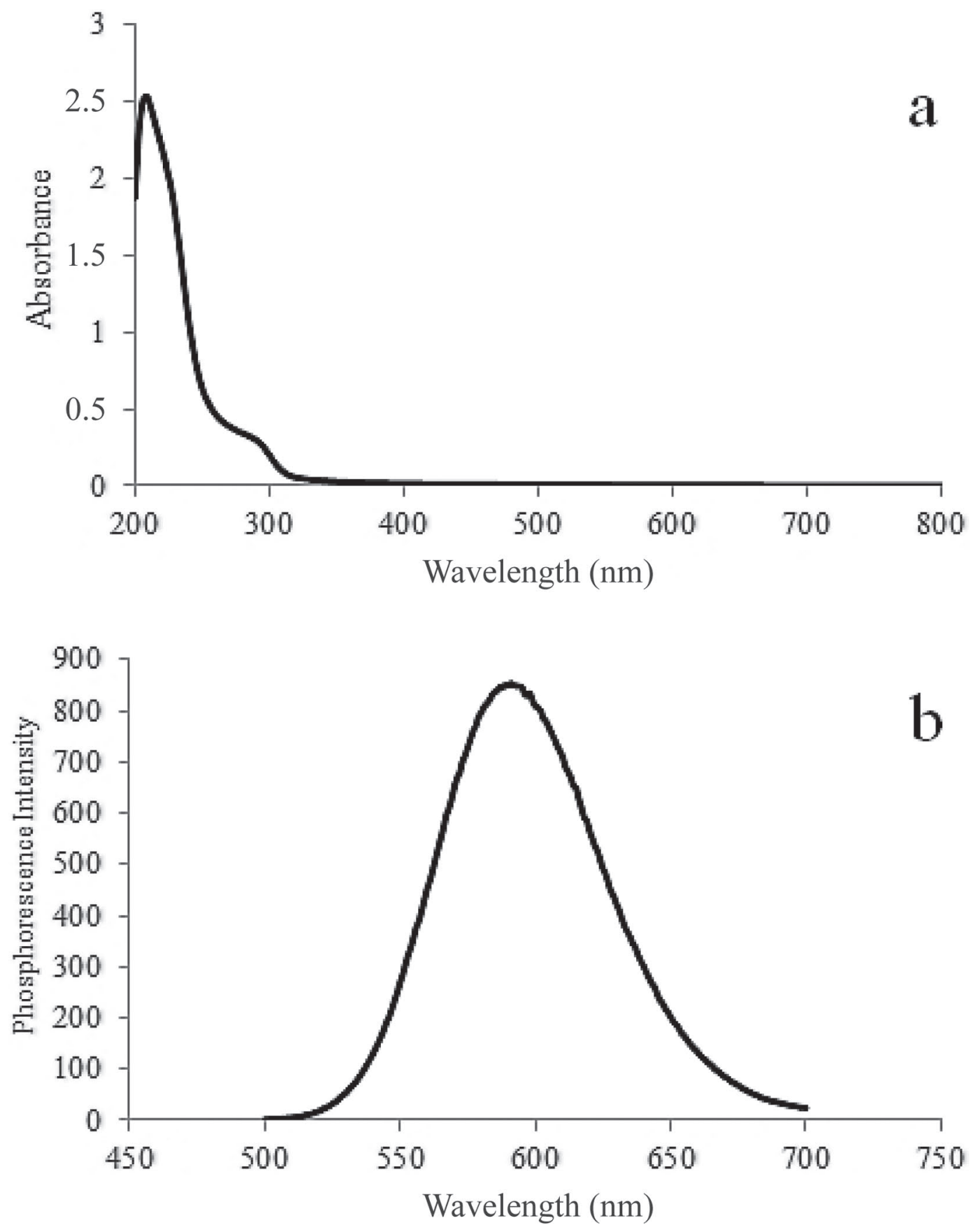

Figure 2. The absorption spectrum (a) and phosphorescence spectrum (b) of Mn-doped zinc sulfide (ZnS) quantum dots.

sis of MEL in dairy products without potential interferences.

\section{Validation of the Method}

Linearity. To determine MEL in dairy product, we investigated the effect of MEL on RTP intensity of QD. The RTP intensity of Mn-doped ZnS QD was sensitive to MEL. Measurements of the phosphorescence spectra were obtained in $10 \mathrm{mM}$ phosphate buffer at $\mathrm{pH}$ 7.4. As shown in Figure 5, the quenching of RTP intensity of QD was dependent on the concentration of MEL. We detected a linear relationship between the quenched RTP intensity $(\Delta \mathrm{P})$ and the concentration of MEL in the range of 50 to $500 \mathrm{ng} / \mathrm{mL}$, with a correlation coefficient of 0.995 . The linear regression was $\Delta \mathrm{P}=0.708 \mathrm{C}$ 

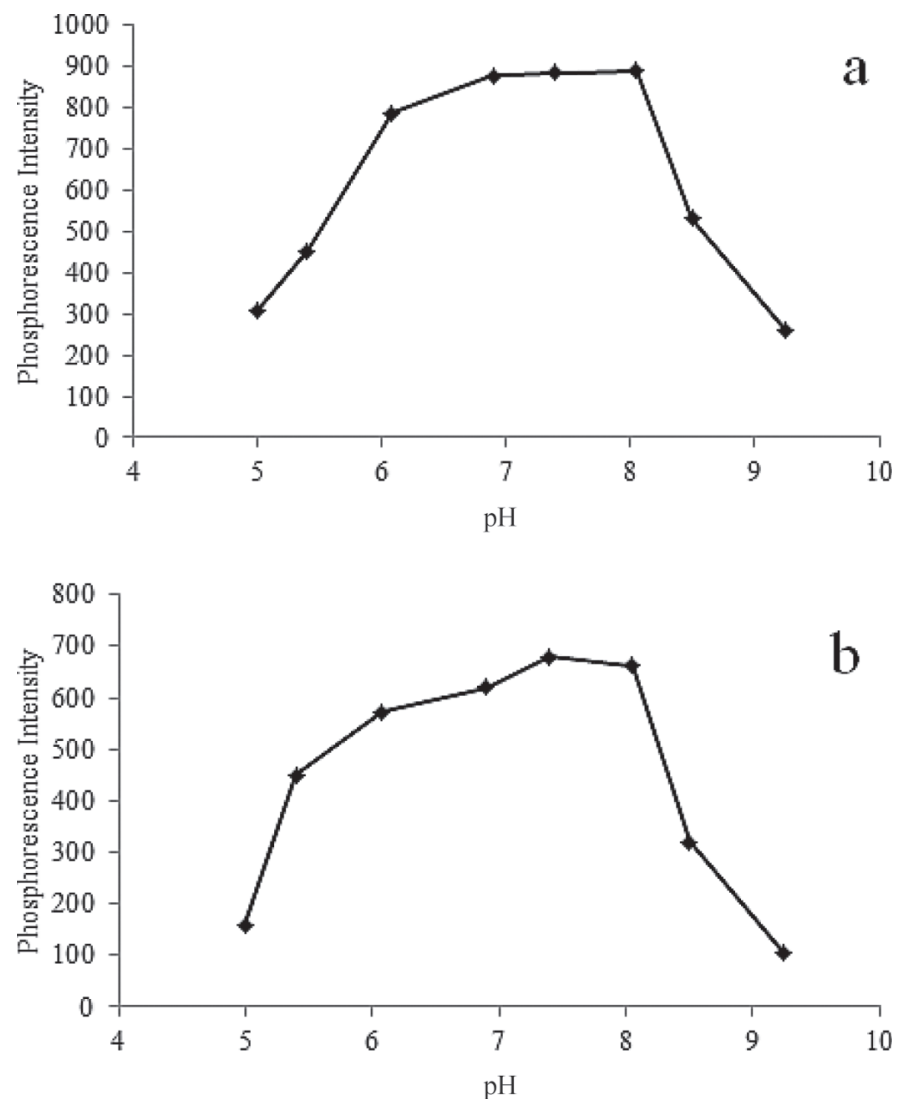

Figure 3. Effect of the $\mathrm{pH}$ on the room-temperature phosphorescence (RTP) intensity of Mn-doped zinc sulfide $(\mathrm{ZnS})$ quantum dots (a) and the quenched RTP intensity of quantum dots with melamine (b).

+44.06 , where $\mathrm{C}$ was the concentration of MEL (ng/ $\mathrm{mL}$ ). The analytical data for the calibration graph are listed in Table 1.

Precision. System repeatability was determined by 5 replicate applications and measurement of phosphorescence intensity. Method repeatability was obtained from relative standard deviation (\%) values obtained by repeating the assay 5 times on the same day (intra-day precision). Inter-day precision was assessed by assaying samples on 3 different days. The results of intra- and inter-day precision studies are shown in Table 1.

Limits of Detection and Quantification. Several approaches are given in the International Conference on Harmonisation of Technical Requirements for Registration of Pharmaceuticals for Human Use (ICH) guideline (ICH, 2014) to determine limit of detection (LOD) and limit of quantification (LOQ). In this study, the LOD and LOQ were calculated from the equations of LOD $=3 s / m$ and $\mathrm{LOQ}=10 \mathrm{~s} / \mathrm{m}$ (Swartz and Krull, 1997), where $s$ is the standard deviation for 5 replicates and $m$ is the slope of the calibration curve. The LOD and LOQ values were calculated as 5.95 and $19.8 \mathrm{ng} / \mathrm{mL}$,

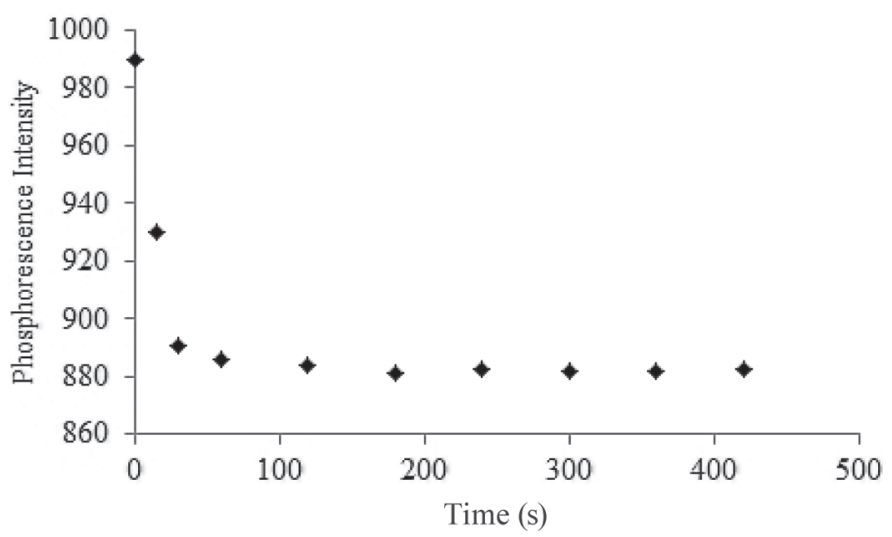

Figure 4. Effect of the reaction time on the room-temperature phosphorescence (RTP) intensity of Mn-doped zinc sulfide (ZnS) quantum dots ( $0 \mathrm{~s}$ is RTP signal of quantum dots only).

respectively (Table 1). Under optimal conditions, this LOD value is low enough for the determination of MEL in milk products; the maximum MEL concentrations allowed by TFC are 2.5 and $1 \mathrm{mg} / \mathrm{kg}$ for food (other than infant formula) and powdered infant formula, respectively.

Recovery. To test the accuracy and reproducibility of the proposed method, recovery studies were performed by spiking samples with an appropriate amount of the stock solution of MEL. The recovery values were calculated using the related regression equation after 3 measurements. The recovery values were in an acceptable range of 96 to $104 \%$ (Table 2).

\section{Sample Analysis}

Under optimal conditions, the proposed method was used to detect MEL in milk products, including followon milk, cheese, cream, coffee creamer, and yogurt. No interfering peaks were observed from any of the ingredients of the assayed samples (Table 2). As seen in the table, the detected values were below the acceptable

Table 1. Statistical evaluation of calibration data for quantitative determination of melamine

\begin{tabular}{lc}
\hline Item & Value \\
\hline Linearity range $(\mathrm{ng} / \mathrm{mL})$ & $50-500$ \\
Slope & 0.71 \\
Intercept & 44.06 \\
Correlation coefficient & 0.995 \\
SE of slope & 0.11 \\
SE of intercept & 3.20 \\
Limit of detection $(\mathrm{ng} / \mathrm{mL})$ & 5.95 \\
Limit of quantification $(\mathrm{ng} / \mathrm{mL})$ & 19.83 \\
Inter-day precision $(3 \mathrm{~d}, \mathrm{n}=5 ; \mathrm{RSD} \%)^{1}$ & 0.15 \\
Intra-day precision $(\mathrm{n}=5 ; \mathrm{RSD} \%)^{1}$ & 0.49 \\
\hline
\end{tabular}

${ }^{1} \mathrm{RSD}=$ relative standard deviation. 


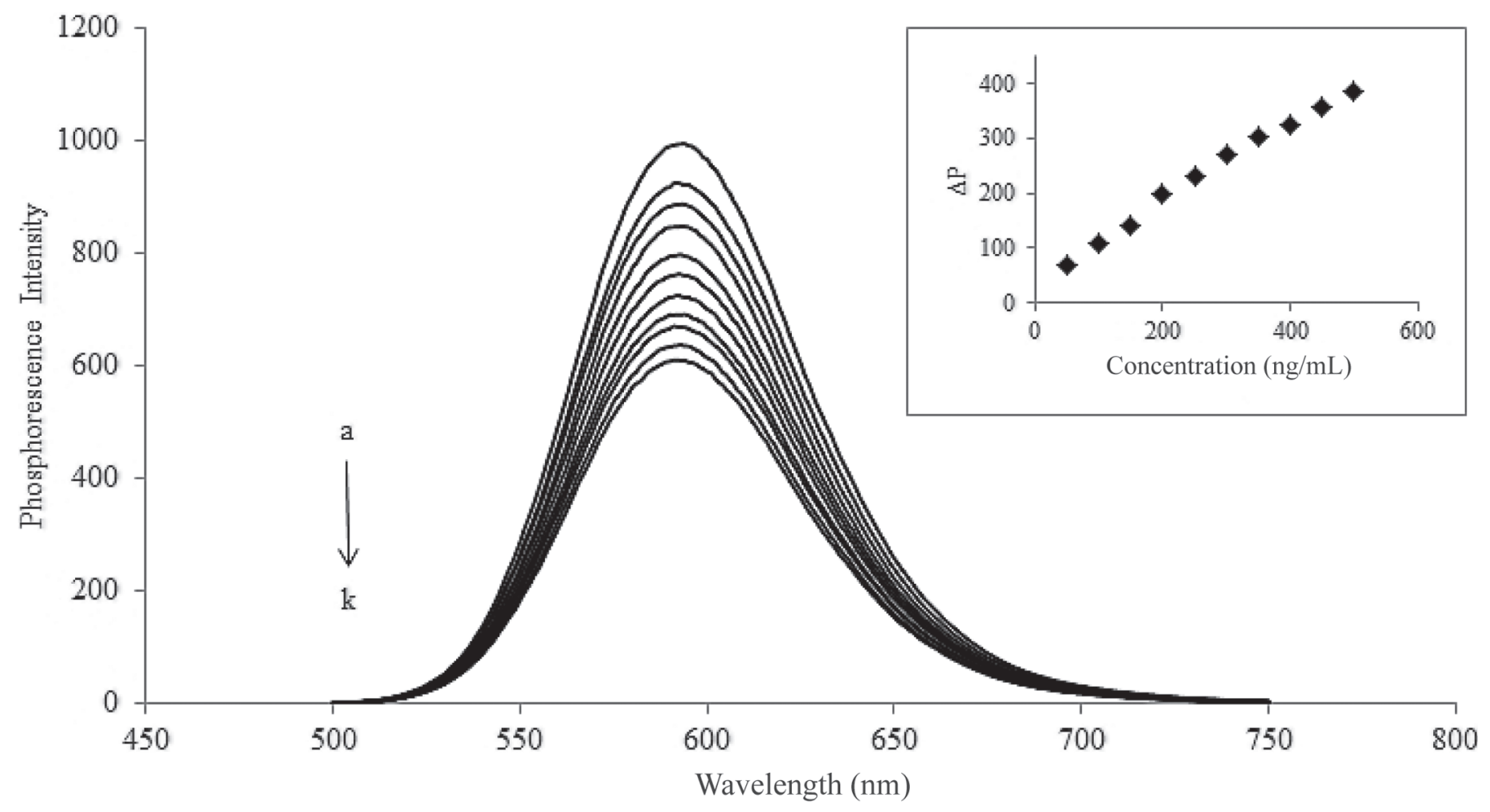

Figure 5. Effect of melamine concentration on the room-temperature phosphorescence (RTP) intensity of Mn-doped zinc sulfide (ZnS) quantum dots. The concentrations of melamine were (a) 0, (b) 50, (c) 100, (d) 150, (e) 200, (f) 250, (g) 300, (h) 350, (i) 400, (j) 450, and (k) 500 ng/ $\mathrm{mL}$. Delta $\mathrm{P}(\Delta \mathrm{P})$ is the quenched RTP intensity, which is the difference between phosphorescence intensity of QD before and after addition of MEL. Inset figure $(\Delta \mathrm{P})$ shows quenched RTP intensity.

values. The literature contains a few reports on MEL detection using different methods, as summarized in Table 3. Our proposed method had good sensitivity, a wide linear range, a low RSD, and high recovery percentage compared with other techniques.

\section{Response Mechanism}

Quenching of phosphorescence signal refers to the decrease of phosphorescence intensity of a phosphorescent molecule due to molecular interactions. The

Table 2. Results of samples and recovery analysis of melamine (MEL) in different dairy products

\begin{tabular}{|c|c|c|c|c|c|}
\hline Sample & MEL level & $\begin{array}{c}\text { Added } \\
(\mathrm{ng} / \mathrm{mL})\end{array}$ & $\begin{array}{c}\text { Recovered } \\
(\mathrm{ng} / \mathrm{mL})\end{array}$ & $\begin{array}{l}\mathrm{RSD}^{1} \\
(\%)\end{array}$ & $\begin{array}{c}\text { Recovery } \\
(\%)\end{array}$ \\
\hline \multirow{3}{*}{$\begin{array}{l}\text { Coffee creamer } \\
(\mathrm{ng} / \mathrm{g})\end{array}$} & \multirow[t]{3}{*}{866} & 50.0 & 50.0 & 0.22 & 100 \\
\hline & & 100.0 & 103.9 & 0.86 & 103.9 \\
\hline & & 150.0 & 152.3 & 0.87 & 101.5 \\
\hline \multirow{3}{*}{$\begin{array}{l}\text { White cheese } \\
(\mathrm{ng} / \mathrm{g})\end{array}$} & \multirow[t]{3}{*}{$<\mathrm{DL}^{2}$} & 50.0 & 48.1 & 0.35 & 96.3 \\
\hline & & 100.0 & 104.7 & 0.34 & 104.7 \\
\hline & & 150.0 & 151.0 & 0.45 & 100.6 \\
\hline \multirow{3}{*}{$\begin{array}{l}\text { Yogurt } \\
(\mathrm{ng} / \mathrm{g})\end{array}$} & \multirow[t]{3}{*}{1,275} & 50.0 & 50.1 & 0.80 & 100.3 \\
\hline & & 100.0 & 104.0 & 0.91 & 104.0 \\
\hline & & 150.0 & 151.4 & 0.46 & 101.1 \\
\hline \multirow{3}{*}{$\begin{array}{l}\text { Cream } \\
(\mathrm{ng} / \mathrm{g})\end{array}$} & \multirow[t]{3}{*}{1,531} & 50.0 & 50.2 & 0.39 & 100.4 \\
\hline & & 100.0 & 103.4 & 0.48 & 103.4 \\
\hline & & 150.0 & 150.7 & 0.86 & 100.5 \\
\hline \multirow{3}{*}{$\begin{array}{l}\text { Follow-on milk } \\
(\mathrm{ng} / \mathrm{mL})\end{array}$} & \multirow[t]{3}{*}{$<\mathrm{DL}$} & 50.0 & 48.8 & 0.89 & 97.6 \\
\hline & & 100.0 & 103.8 & 0.38 & 103.8 \\
\hline & & 150.0 & 150.7 & 0.85 & 100.4 \\
\hline
\end{tabular}

${ }^{1}$ Relative standard deviation.

${ }^{2}<\mathrm{DL}=$ below detection limit. 


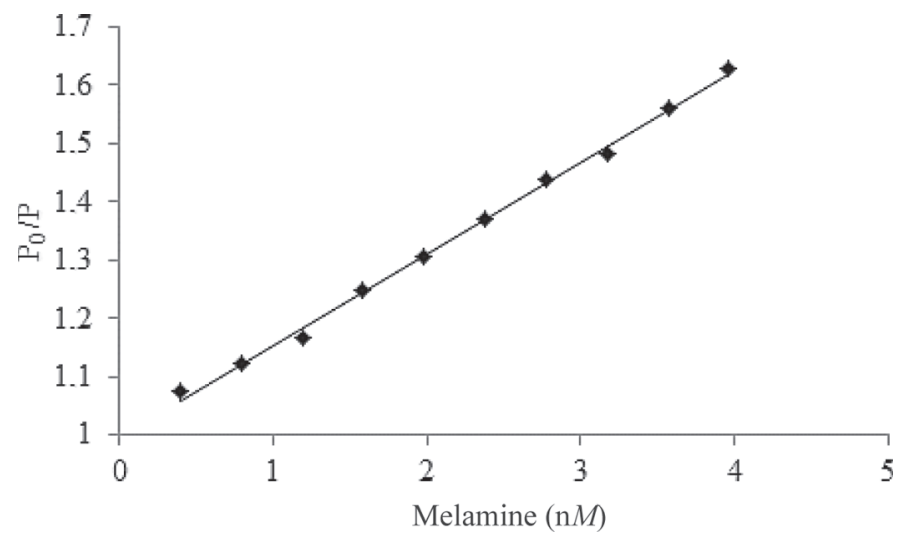

Figure 6. Stern-Volmer plot for the phosphorescence quenching effect of melamine on Mn-doped zinc sulfide (ZnS) quantum dots (concentration of melamine ranged from 0.4 to $4 \mathrm{n} M$ in $10 \mathrm{~m} M$ phosphate buffer, $\mathrm{pH}$ 7.4); $\mathrm{P}_{0}$ and $\mathrm{P}$ are the phosphorescence intensities of quantum dots in the absence and presence of quencher, respectively.

mechanism is generally 1 of 2 types: dynamic or static quenching (Lakowicz, 1999). In dynamic quenching, the phosphorescent molecule and quencher contact when the molecules are at the excited state and the phosphorescent molecule returns to the ground state without emission. In static quenching, however, the phosphorescent molecule and quencher form a nonphosphorescent complex. To investigate the quenching mechanism, the phosphorescence quenching data from our study were analyzed using the Stern-Volmer equation (Eq. [2]; Lakowicz, 1999):

$$
\mathrm{P}_{0} / \mathrm{P}=1+\mathrm{K}_{\mathrm{app}}[\mathrm{Q}]
$$

where $\mathbf{P}_{0}$ and $\mathbf{P}$ are the phosphorescence intensities of QD in the absence and presence of quencher, respectively; $K_{a p p}$ is the Stern-Volmer quenching constant; and $[\mathrm{Q}]$ is the concentration of the quencher. The SternVolmer quenching constant, $\mathrm{K}_{\mathrm{app}}$, was determined by linear regression of a plot of $\mathrm{P}_{0} / \mathrm{P}$ against $[\mathrm{Q}]$.

The relationship between $\mathrm{P}_{0} / \mathrm{P}$ and the increasing concentration of MEL presented a linear curve with a correlation coefficient of $\mathrm{r}=0.9975$ in the range of 0.4 to $4 \mathrm{n} M$, which permits its use as a probe to determine MEL (Figure 6). The linear regression equation was $\mathrm{P}_{0} / \mathrm{P}=0.1571[\mathrm{Q}]+0.9973$, where $[\mathrm{Q}]$ is the concentration $(\mathrm{n} M)$ of MEL. According to this result, the RTP quenching mechanism was dynamic, and $\mathrm{K}_{\mathrm{app}}$ was found to be $1.5 \times 10^{5} M^{-1}$, indicating that MEL and QD interacted strongly. Melamine has 3 amino groups, which could strongly interact with the QD. Amino acids in samples also interact with QD via their amino groups, but these interactions are much weaker compared with the interaction with MEL, which has multiple strong binding sites. Therefore, the method reported here allows sensitive determination of MEL in milk products without any interference.

\section{CONCLUSIONS}

Melamine is used illegally in protein-rich foods such as dairy products to enhance the protein content, but melamine cannot be detected by Kjeldahl method. Although several methods (e.g., HPLC and GC) have been used to detect melamine in dairy products, these methods are not suitable for routine analysis. For this purpose, we developed a method to use L-cysteinecapped Mn-doped ZnS QD to determine melamine levels in dairy products. The QD were synthesized and identified in the present study; the nanoparticles had excellent phosphorescent properties, and the working mechanism of the QD probe was based on quenching of its phosphorescence intensity. The developed method has some advantages over conventional fluorescence and phosphorescence techniques. First, it avoids interference from autofluorescence or cations such as $\mathrm{Na}^{+}, \mathrm{K}^{+}$, $\mathrm{Mg}^{2+}$, and $\mathrm{Ca}^{2+}$. In addition, it does not require the removal of dissolved oxygen or the addition of surfactant or other chemical modifiers, and no derivatization step is required. The proposed method was used to quantify melamine in cheese, yogurt, cream, coffee creamer, and follow-on milk. Concentrations of melamine could be directly monitored according to the changing of RTP

Table 3. Comparison of the proposed method with different techniques reported for the determination of melamine

\begin{tabular}{llccl}
\hline Method & $\begin{array}{l}\text { Linear range } \\
(\mathrm{ng} / \mathrm{mL})\end{array}$ & $\begin{array}{r}\text { Limit of } \\
\text { detection } \\
(\mathrm{ng} / \mathrm{mL})\end{array}$ & $\begin{array}{c}\mathrm{RSD}^{1} \\
(\%)\end{array}$ & Reference \\
\hline Proposed method & $50-500$ & 5.9 & 0.1 & This work \\
Fluorescence & $25-1,000$ & 19.0 & 1.6 & Huang et al., 2010 \\
HPLC & $50-10,000$ & 8.1 & 0.8 & Finete et al., 2014 \\
GC-MS & $50-800$ & 10.0 & 7.9 & Pan et al., 2013 \\
Electrochemistry & $630-11,350$ & 107.0 & 1.0 & Araujo and Paixao, 2014 \\
Spectroscopy & $100-3,780$ & 80.0 & 3.6 & Chansuvarn et al., 2013 \\
\hline
\end{tabular}

${ }^{1}$ Relative standard deviation. 
intensity of QD. Our proposed method is sensitive, selective, fast, and inexpensive, and it has a low detection limit.

\section{REFERENCES}

Araujo, W. R., and T. R. L. C. Paixao. 2014. Use of copper electrode for melamine quantification in milk. Electrochim. Acta 117:379384 .

Beltran-Martinavarro, B., J. Peris-Vicente, S. Carda-Broch, and J. Esteve-Romero. 2014. Development and validation of a micellar liquid chromatography-based method to quantify melamine in swine kidney. Food Contr. 46:168-173.

Cao, X., F. Shen, M. Zhang, J. Guo, Y. Luo, X. Li, and H. Liu. 2013. Efficient inner filter effect of gold nanoparticles on the fluorescence of CdS quantum dots for sensitive detection of melamine in raw milk. Food Contr. 34:221-229.

Cao, X., F. Shen, M. Zhang, and C. Sun. 2014. Rapid and highly sensitive melamine sensing based on the efficient inner filter effect of $\mathrm{Ag}$ nanoparticles on the fluorescence of eco-friendly ZnSe quantum dots. Sensor Actuat. Biol. Chem. 202:1175-1182.

Chang, L., R. She, L. Ma, H. You, F. Hu, T. Wang, X. Ding, Z. Guo, and M. H. Soomro. 2014. Acute testicular toxicity induced by melamine alone or a mixture of melamine and cyanuric acid in mice. Reprod. Toxicol. 46:1-11.

Chansuvarn, W., S. Panich, and A. Imyim. 2013. Simple spectrophotometric method for determination of melamine in liquid milks based on green Mannich reaction. Spectrochim. Acta A Mol. Biomol. Spectrosc. 113:154-158.

Duan, H. J., N. Guan, Y. Wu, J. Zhang, J. Ding, and B. Shao. 2011. Identification of biomarkers for melamine-induced nephrolithiasis in young children based on ultra high performance liquid chromatography coupled to time-of-flight mass spectrometry (U-HPLCQ-TOF/MS). J. Chromatogr. B Analyt. Technol. Biomed. Life Sci. 879:3544-3550.

Finete, V. L. M., M. M. Gouvêa, F. F. Marques, and A. D. Netto. 2014. Characterization of new found natural luminescent properties of melamine, and development and validation of a method of high performance liquid chromatography with fluorescence detection for its determination in kitchen plastic ware. Talanta 123:128-134

Fortes, P. R., C. Frigerio, C. I. C. Silvestre, J. L. M. Santos, J. F. C. Lima, and E. A. G. Zagatto. 2011. Cadmium telluride nanocrystals as luminescent sensitizers in flow analysis. Talanta 84:1314-1317.

Gong, Y., H. Wu, and Z. Fan. 2013. Water-soluble Eu(III)-doped ZnS quantum dots for the room-temperature phosphorescence detection of melamine in milk products. Anal. Methods 5:6114-6119.

Guo, Z., X. F. Xu, J. Li, Y. W. Liu, J. Zhang, and C. Yang. 2014. Ordered mesoporous carbon as electrode modification material for selective and sensitive electrochemical sensing of melamine. Sensor Actuat. Biol. Chem. 200:101-108.

Hassani, S., F. Tavakoli, M. Amini, F. Kobarfard, A. Nili-Ahmadabadi, and O. Sabzevari. 2013. Occurrence of melamine contamination in powder and liquid milk in market of Iran. Food Addit. Contam. A Chem. Anal. Control Expo. Risk Assess. 30:413-420.

He, Y., H. F. Wang, and X. P. Yan. 2008. Exploring Mn-doped ZnS quantum dots for the room-temperature phosphorescence detection of enoxacin in biological fluids. Anal. Chem. 80:3832-3837.

Himmelsbach, M., and T. D. Thanh Vo. 2014. Determination of melamine impurities by capillary zone electrophoresis with UV and quadrupole time-of-flight mass spectrometric detection. Electrophoresis 35:1362-1367.

Huang, H., L. Li, Q. Ma, F. Yu-Qi, and Z. K. He. 2010. Determination of melamine in milk by fluorescent spectrophotometry with cetyltrimethylammonium bromide. Chin. J. Anal. Chem. 38:249-252.

ICH (International Conference on Harmonisation). 2014. International Conference on Harmonisation of Technical Requirements for Registration of Pharmaceuticals for Human Use. Accessed Sep. 10, 2014. http://www.ich.org/products/guidelines.html.
Jurado-Sanchez, B., and E. Ballesteros. 2011. Gas chromatographic determination of N-nitrosamines, aromatic amines, and melamine in milk and dairy products using an automatic solid-phase extraction system. J. Agric. Food Chem. 59:7519-7526.

Katou, Y., and X. Z. Wu. 2012. Development of a simple sample pretreatment method for capillary electrophoretic determination of melamine in milks. Bunseki Kagaku 61:419-423.

Khedr, A. 2013. Optimized extraction method for LC-MS determination of bisphenol A, melamine and di(2-ethylhexyl) phthalate in selected soft drinks, syringes, and milk powder. J. Chromatogr. B Analyt. Technol. Biomed. Life Sci. 930:98-103.

Koh, G., R. S. C. Chia, Q. Lin, P. S. Cheow, T. L. Teo, and T. K. Lee. 2011. Determination of melamine in milk powder using gas chromatography-high-resolution isotope dilution mass spectrometry. J. Sep. Sci. 34:3043-3052.

Kong, Y., J. Yuan, Z. Wang, Z. Hou, J. Yu, H. Jin, M. Xie, N. Chang, W. Xu, Y. Zhao, and Y. Tang. 2014. Assay of melamine in milk products with a $\mathrm{pH}$-mediated stacking technique in capillary electrophoresis. J. Sep. Sci. 37:717-724.

Lakowicz, J. R. 1999. Principles of Fluorescence Spectroscopy. 2nd ed. Plenum Press, New York, NY.

Li, C., Y. F. Li, B. Liang, N. Li, and Z. Z. Li. 2013. A simple and sensitive method for the determination of melamine in milk by first derivative UV spectrophotometry coupled with the H-point standard addition method. Anal. Methods 5:5760-5766.

Liu, F., M. Q. Zou, M. Zhang, X. F. Zhang, and M. Li. 2014. Study of fast pretreatment method in detection of melamine in liquid milk using liquid chromatography and raman spectroscopy. Guang $\mathrm{Pu}$ Xue Yu Guang Pu Fen Xi 34:685-688. [In Chinese]

Matsuoka, S., and K. Yoshimura. 2010. Recent trends in solid phase spectrometry:2003-2009.A rewiev. Anal. Chim. Acta 664:1-18.

Pan, X. D., P. G. Wu, D. J. Yang, L. Y. Wang, X. H. Shen, and C. Y. Zhu. 2013. Simultaneous determination of melamine and cyanuric acid in dairy products by mixed-mode solid phase extraction and GC-MS. Food Contr. 30:545-548.

Ren, H. B., and X. P. Yan. 2012. Ultrasonic assisted synthesis of adenosine triphosphate capped manganese-doped $\mathrm{ZnS}$ quantum dots for selective room temperature phosphorescence detection of arginine and methylated arginine in urine based on supramolecular $\mathrm{Mg}^{2+}$-adenosine triphosphate-arginine ternary system. Talanta 97:16-22.

Shin, C., Y. Lim, E. Yoon, and S. Kim. 2014. Detection of adulteration in commercial galactooligosaccharide by flow-injection electrospray ionization tandem mass spectrometry. Food Contr. 36:280-286.

Swartz, M. E., and I. S. Krull. 1997. Analytical Development and Validation, Marcel and Dekker Inc., New York, NY.

Tang, G., L. Du, and X. Su. 2013. Detection of melamine based on fluorescence resonance energy transfer between CdTe QDs and Rhodamine B. Food Chem. 141:4060-4065.

TFC (Turkish Food Codex). 2012. Türk Gıda Kodeksi bulaşanlar yönetmeliğinde değişiklik yapılmasına dair yönetmelik. Accessed Sep. 10, 2014. http://www.resmigazete.gov.tr/eskiler/ 2012/12/20121219-10.htm. (In Turkish).

Vachirapatama, N., and S. Maitresorasun. 2013. Simultaneous determination of melamine, ammelide, ammeline and cyanuric acid in milk products by micellar electrokinetic chromatography. J. Food Drug Anal. 21:66-72.

Vallejo-Cordoba, B., and F. Aaron. 2010. Capillary electrophoresis for the analysis of contaminants in emerging food safety issues and food traceability. Electrophoresis 31:2154-2164.

Vara Messler, M. V., D. C. Cremonezzi, E. A. Soria, and A. R. Eynard. 2012. Nutritional chemoprevention of urinary tract tumors (UTT) induced by lithogenic agents: Risk for UTT in children exposed to melamine-contaminated milk formulas. J. Environ. Sci. Health C Environ. Carcinog. Ecotoxicol. Rev. 30:174-187.

Wang, G., Y. Zhu, X. He, L. Chen, L. Wang, and X. Zhang. 2014. Colorimetric and visual determination of melamine by exploiting the conformational change of hemin G-quadruplex-DNAzyme. Mikrochim. Acta 181:411-418. 
Wang, G. L., H. J. Jiao, X. Y. Zhu, Y. M. Dong, and Z. J. Li. 2012. Enhanced fluorescence sensing of melamine based on thioglycolic acid-capped CdS quantum dots. Talanta 93:398-403.

Wang, H. F., Y. He, T. R. Ji, and X. P. Yan. 2009. Surface molecular imprinting on Mn-doped $\mathrm{ZnS}$ quantum dots for room-temperature phosphorescence optosensing of pentachlorophenol in water. Anal. Chem. 81:1615-1621.

Wong, Y. L., and C. S. Mok. 2013. A single analytical procedure for the simultaneous and confirmatory determination of melamine and related compounds in various food matrices by isotope dilution gas chromatography-mass spectrometry (ID-GC-MS). Anal. Methods 5:2305-2314.

Wu, Y., and Z. Yu. 2013. Analytical chemistry, toxicology, epidemiology and health impact assessment of melamine in infant formula: Recent progress and developments. Food Chem. Toxicol. $56: 325-335$.

Xu, G., H. Zhang, M. Zhong, T. Zhang, X. Lu, and X. Kan. 2014. Imprinted sol-gel electrochemical sensor for melamine direct recognition and detection. J. Electroanal. Chem. 713:112-118.
Xue, J., P. T. Lee, and R. G. Compton. 2014. Electrochemical detection of melamine. Electroanalysis 26:1454-1460.

Yan, H., X. Cheng, N. Sun, T. Cai, R. Wu, and K. Han. 2012. Rapid and selective screening of melamine in bovine milk using molecularly imprinted matrix solid-phase dispersion coupled with liquid chromatography-ultraviolet detection. J. Chromatogr. B Analyt. Technol. Biomed. Life Sci. 908:137-142.

Zhang, M., X. Cao, H. Li, F. Guan, J. Guo, F. Shen, Y. Luo, C. Sun, and L. Zhang. 2012. Sensitive fluorescent detection of melamine in raw milk based on the inner filter effect of Au nanoparticles on the fluorescence of CdTe quantum dots. Food Chem. 135:1894-1900.

Zhang, S., Z. Yu, N. Hu, Y. Sun, Y. Suo, and J. You. 2014. Sensitive determination of melamine leached from tableware by reversed phase high-performance liquid chromatography using 10-methylacridone-2-sulfonyl chloride as a pre-column fluorescent labeling reagent. Food Contr. 39:25-29. 